\title{
Risk of failure in pediatric ventriculoperitoneal shunts placed after abdominal surgery
}

\author{
Joshua D. Burks, BA, ${ }^{1}$ Andrew K. Conner, MD, ${ }^{1}$ Robert G. Briggs, BS, ${ }^{1}$ Chad A. Glenn, MD, \\ Phillip A. Bonney, MD, ${ }^{1}$ Ahmed A. Cheema, MD, ${ }^{1}$ Sixia Chen, PhD, ${ }^{2}$ Naina L. Gross, MD, ${ }^{1}$ and \\ Timothy B. Mapstone, MD'
}

Departments of ${ }^{1}$ Neurosurgery and ${ }^{2}$ Biostatistics, University of Oklahoma Health Sciences Center, Oklahoma City, Oklahoma

OBJECTIVE Experience has led us to suspect an association between shunt malfunction and recent abdominal surgery, yet information about this potential relationship has not been explored in the literature. The authors compared shunt survival in patients who underwent abdominal surgery to shunt survival in our general pediatric shunt population to determine whether such a relationship exists.

METHODS The authors performed a retrospective review of all cases in which pediatric patients underwent ventriculoperitoneal shunt operations at their institution during a 7-year period. Survival time in shunt operations that followed abdominal surgery was compared with survival time of shunt operations in patients with no history of abdominal surgery. Univariate and multivariate analyses were used to identify factors associated with failure.

RESULTS A total of 141 patients who underwent 468 shunt operations during the period of study were included; 107 of these 141 patients had no history of abdominal surgery and 34 had undergone a shunt operation after abdominal surgery. Shunt surgery performed more than 2 weeks after abdominal surgery was not associated with time to shunt failure $(p=0.86)$. Shunt surgery performed within 2 weeks after abdominal surgery was associated with time to failure (adjusted HR 3.6, 95\% Cl 1.3-9.6).

CONCLUSIONS Undergoing shunt surgery shortly after abdominal surgery appears to be associated with shorter shunt survival. When possible, some patients may benefit from shunt placement utilizing alternative termini.

https://thejns.org/doi/abs/10.3171/2016.10.PEDS16377

KEY WORDS ventriculoperitoneal; shunt; malfunction; failure; surgery; abdominal; pediatric; percutaneous endoscopic gastrostomy; hydrocephalus

$\mathrm{V}$ ENTRICULOPERITONEAL (VP) shunts in pediatric patients often present a challenge for neurosurgeons given the need for reoperation. Despite its shortcomings, VP shunting remains the mainstay of treatment for most children with hydrocephalus. Many studies in recent years have sought to identify modifiable risk factors for shunt malfunction. Shunt malfunctions are frequent and costly, and recent studies have shown that between $25 \%$ and $60 \%$ of pediatric shunt patients will experience shunt failure within 1 year of shunt placement. 1,10,13,20,35 $^{2}$

Abdominal surgery is common in shunt-treated pediatric patients. For instance, myelomeningocele patients often require operations to augment bowel and/or bladder function..$^{16}$ At our institution, experience led us to suspect that VP shunt malfunction occurs more frequently when the shunt is placed after an abdominal procedure. There is little information in the literature regarding this subject, and it is unclear whether these patients are actually at additional risk.

Considering the relationship between abdominal surgery and shunt failure may serve to optimize surgical decision-making. To better our understanding, we compared survival time in shunt operations that followed abdominal surgery to survival time in shunt operations in patients with no history of abdominal surgery.

\section{Methods}

\section{Patient Selection and Treatment}

We retrospectively reviewed data on all cases involving

ABBREVIATIONS PEG = percutaneous endoscopic gastrostomy; VP = ventriculoperitoneal.

SUBMITTED July 1, 2016. ACCEPTED October 10, 2016.

INCLUDE WHEN CITING Published online February 17, 2017; DOI: 10.3171/2016.10.PEDS16377. 
pediatric patients undergoing VP shunt placement or revision at our institution between January 2008 and December 2015. Complete records were gathered with respect to all operations on each patient during the period of study. Patients without continuity (those who received operations at other institutions between visits to our institution) were excluded from the study. Patients with alternative distal catheter termination sites were also excluded. This review was completed with approval from our institutional review board.

VP shunts were placed by 1 of 9 neurosurgeons via the occipital or frontal approach. Neuroendoscopy, image guidance, and antibiotic-impregnated catheters were used for ventricular placement according to attending preference. After tunneling, conventional open placement was performed for the peritoneal portion of the catheter. If the position of the distal catheter remained in question following insertion, a general surgeon verified its placement with laparoscopy. Patients were seen in clinic at 3 and 6 months postoperatively, then at 12-month intervals.

\section{Studied Variables}

Abdominal surgery was defined as any procedure requiring entry into the abdominal cavity. This included, but was not limited to, inguinal herniorrhaphy, appendectomy, cholecystectomy, lysis of adhesions, and fundoplication. Emergent operations involving viscous perforation were not included, as the likelihood of bacterial seeding would have precluded placement of a distal catheter acutely. Urological procedures not requiring entry into the abdomen (circumcision, hypospadias repair, etc.) were not recorded as abdominal surgeries. Any patient who underwent abdominal surgery with a shunt in place was also excluded from the study. Abdominal surgery was noted to be either open (laparotomy) or laparoscopic. Data on other variables, including age, sex, and etiology of hydrocephalus, were collected for every patient to allow for identification of any confounding factors in our analysis.

Any shunt surgery was recorded as a first-time placement or a revision of an existing shunt. In patients with existing shunts, distal catheters were often externalized prior to planned abdominal procedures, and then replaced in the abdomen at a later date. Replacement into the abdomen of an externalized shunt was considered a replacement of an existing shunt. Malfunction/revision was further characterized as either proximal catheter or distal catheter, or involving multiple components. Flow of CSF was assessed through the valve and through proximal and distal catheters after disconnection from the valve in all revision surgeries. Isolated valve failure was uncommon and was analyzed together with combined (catheter tubing + valve) and complete revisions of the shunt system.

\section{Outcome Assessment}

Many patients underwent multiple shunt surgeries, and in some cases, multiple abdominal surgeries. Out of concern for overrepresentation by variables affecting patients undergoing multiple surgeries, only the first shunt observation for each patient was included in our final analysis. Using one observation per patient enabled a random distribution of additional risks for short-term failure. An observation was defined as the time from shunt placement or revision to shunt revision or removal.

Shunt malfunction was recorded as infection in the presence of positive cultures and/or clinical diagnosis. All cultures were incubated for 7 days to include sensitivity for propionobacteria. ${ }^{3}$ Clinical diagnosis was made in the presence of symptoms (fever, nausea, vomiting, lethargy, shunt malfunction, etc.) and the absence of another identifiable infectious source. Wound erosion was by definition categorized as infection, whereas abdominal pseudocyst was only considered infection if the given criteria were met.

\section{Statistical Analysis}

Continuous variables were reported as means with standard deviations unless otherwise specified. Categorical variables were reported using frequencies and percentages. Each variable was analyzed with the primary outcome of first VP shunt failure in univariate analysis. Between-group differences were analyzed using the Wilcoxon rank-sum test. Time to shunt failure was censored in cases of patient relocation, shunt removal not related to malfunction, or death unrelated to shunt malfunction.

Cox proportional hazards analysis was performed to model shunt failure hazard. A variable was excluded from the model if its removal resulted in no significant difference in interpretation of other variables. We decided a priori to include the following 2 variables independent of univariate analysis results: 1) age at the time of shunt placement/revision (because of the association of age with shunt failure given in the literature $8,14,27,45$ ) and 2) etiology of hydrocephalus (given the relationship between myelomeningocele and early revision ${ }^{29}$ ). The final multivariate analysis results are presented as hazard ratios with $95 \%$ confidence intervals. The proportional hazards model assumption was tested for all variables by plotting Schoenfeld residuals, and no time-dependent cofactors were identified.

A p value $\leq 0.05$ was considered statistically significant. All data analysis was conducted using SAS (version 9.4, SAS Institute).

\section{Results}

\section{Patient Population}

A total of 468 shunt operations were performed on 141 patients included in this study. Of these patients, 107 (76\%) had no history of abdominal surgery, and 34 (24\%) had undergone abdominal surgery prior to their shunt operation. The patients' mean age was $3.7 \pm 4.8$ years (range 2 days-17 years). Diagnosis of infection was made in 16 $(11 \%)$ of 141 cases. The mean follow-up time for the entire group of 141 patients was $55.9 \pm 37.3$ months. A summary of demographic and clinical characteristics, including types of abdominal surgeries performed and prevalent etiologies of hydrocephalus, is presented in Table 1.

Shunt operations performed more than 2 weeks after abdominal surgery were not associated with significantly different shunt survival times when compared with shunt operations in patients with no history of abdominal surgery $(\mathrm{p}=0.86)$, as shown in Table 2 . Consequently, all 
TABLE 1. Characteristics of patients who underwent shunt operations

\begin{tabular}{|c|c|}
\hline Characteristic & Value \\
\hline Total shunt procedures & 468 \\
\hline Total no. of pts/1st observations & 141 \\
\hline No abdominal op & $107(76 \%)$ \\
\hline Abdominal op & $34(24 \%)$ \\
\hline Open & $22(65 \%)$ \\
\hline Laparoscopic & $12(35 \%)$ \\
\hline \multicolumn{2}{|l|}{ Types of abdominal op } \\
\hline Ex-lap & $6(18 \%)$ \\
\hline Herniorrhaphy & $10(29 \%)$ \\
\hline Fundoplication & $3(9 \%)$ \\
\hline Cystoplasty & $3(9 \%)$ \\
\hline Appendectomy & $1(3 \%)$ \\
\hline Cholecystectomy & $2(6 \%)$ \\
\hline PEG tube placement & $7(20 \%)$ \\
\hline Other & $2(6 \%)$ \\
\hline \multicolumn{2}{|l|}{ Sex } \\
\hline Male & $82(58 \%)$ \\
\hline Female & $59(42 \%)$ \\
\hline \multicolumn{2}{|l|}{ Age } \\
\hline Mean \pm SD (yrs) & $3.7 \pm 4.8$ \\
\hline Range (yrs) & $0.0-17.9$ \\
\hline \multicolumn{2}{|l|}{ Etiology of $\mathrm{HC}$} \\
\hline Spinal dysraphism & $42(30 \%)$ \\
\hline Tumor & $10(7 \%)$ \\
\hline IVH & $31(22 \%)$ \\
\hline Other & $57(40 \%)$ \\
\hline Unknown & $1(1 \%)$ \\
\hline Follow-up (mos), mean \pm SD & $55.9 \pm 37.3$ \\
\hline Shunt infection, no. of observations & $16 / 141(11 \%)$ \\
\hline
\end{tabular}

Ex-lap = exploratory laparotomy; $\mathrm{HC}=$ hydrocephalus; IVH = intraventricular hemorrhage; pt $=$ patient.

remaining analyses were performed including only patients undergoing abdominal surgery within the 2 weeks immediately preceding their shunt surgery and those with no history of abdominal surgery (Fig. 1).

\section{Analysis of Risk Factors}

In Table 3, the proportion of failed shunts relative to VP shunt operations for each variable is given for direct comparison, and survival analyses were used to generate corresponding $\mathrm{p}$ values. Failure occurred following $6(86 \%)$ of 7 shunt operations performed within 2 weeks after abdominal surgery, compared with $80(75 \%)$ of 107 shunt operations not related to abdominal surgery $(\mathrm{p}=$ $0.02)$. Failure occurred in $56(93 \%)$ of 60 patients aged 0-6 months, compared with $6(54 \%)$ of 11 patients aged 6 months to 2 years and 24 of (56\%) 43 patients aged 2 years to 18 years $(\mathrm{p}<0.01)$; and in $31(82 \%)$ of 38 patients who were treated with CSF shunting for hydrocephalus associated with spinal dysraphism compared with 55 (67\%)
TABLE 2. Shunt survival with remote history of abdominal surgery

\begin{tabular}{ccc}
\hline $\begin{array}{c}\text { Time Since Abdominal Op } \\
\text { at Placement/Revision }\end{array}$ & Failures & p Value \\
\hline 2 wks-6 mos & $6 / 11(55 \%)$ & 0.86 \\
\hline 6 mos-2 yrs & $9 / 16(71 \%)$ & \\
\hline Control group & $80 / 107(75 \%)$ & \\
\hline
\end{tabular}

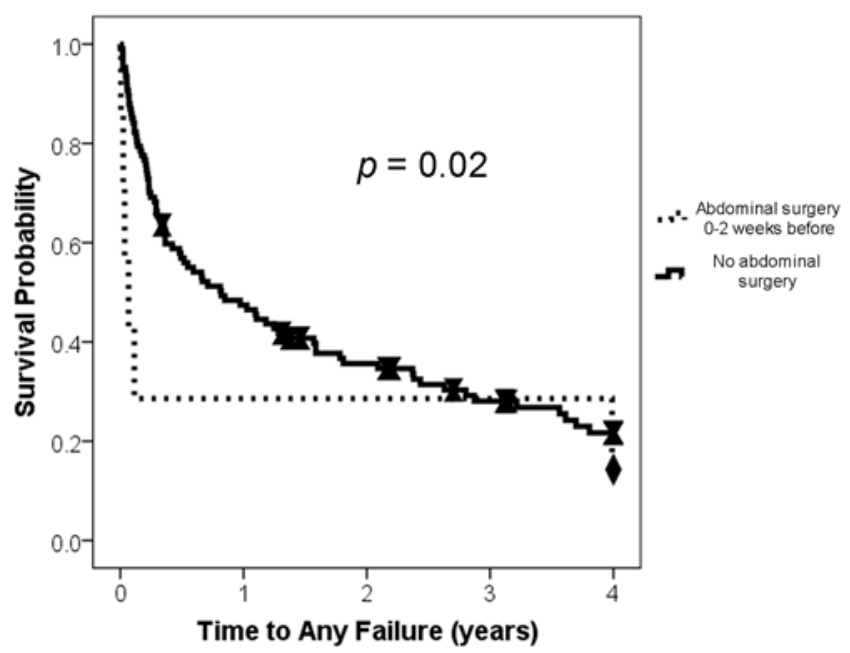

FIG. 1. Kaplan-Meier survival analysis comparing shunt survival in patients who had shunt operations within 2 weeks after abdominal surgery to shunt survival in patients who never underwent abdominal surgery.

of 76 patients who were being treated for hydrocephalus of other etiologies $(\mathrm{p}=0.14)$. Failure also occurred in 66 (92\%) of 72 first-placement shunts, compared with $6(38 \%)$ of 16 proximally revised shunts, 4 (40\%) of 10 distally revised shunts, and $10(62 \%)$ of 16 completely revised shunts $(\mathrm{p} \leq 0.01)$.

\section{Multivariate Analysis}

All variables found to have a significant association with time to shunt failure in univariate analysis, as well as those decided upon a priori, were included in the proportional hazards model. Three risk factors were found to have an independent association with time to shunt failure: abdominal surgery within 2 weeks before shunt operation (adjusted HR 3.6, 95\% CI 1.3-9.6); shunting secondary to spinal dysraphism (adjusted HR 1.6, 95\% CI 1.1-2.6); and first-time shunt placements (adjusted HR 5.8, 95\% CI 2.3-14.5). These are given in Table 4.

\section{Patients Who Underwent Shunt Surgery Within 2 Weeks After Abdominal Surgery}

Additional details of the 7 patients who underwent a shunt operation within 2 weeks after abdominal surgery are given in Table 5. Two patients experienced shunt survival beyond 1 year. The remaining 5 patients experienced failure within 6 weeks, and all had failure of the distal catheter. Of these 5 patients, 1 (20\%) had failure due to 
TABLE 3. Association between variables and time to shunt malfunction

\begin{tabular}{ccc}
\hline \multicolumn{1}{c}{ Covariate } & Failures & p Value \\
\hline Previous abdominal op & & 0.02 \\
\hline$\leq 2$ wks earlier & $6 / 7(86 \%)$ & \\
\hline Control group & $80 / 107(75 \%)$ & \\
\hline Age & & $<0.01$ \\
\hline $0-6$ mos & $56 / 60(93 \%)$ & \\
\hline 6 mos-2 yrs & $6 / 11(54 \%)$ & \\
\hline 2 yrs-18 yrs & $24 / 43(56 \%)$ & \\
\hline Sex & & \\
\hline Female & $35 / 50(70 \%)$ & \\
\hline Male & $51 / 64(80 \%)$ & \\
\hline Etiology of HC & & \\
\hline Spinal dysraphism & $31 / 38(82 \%)$ & \\
\hline Other & $55 / 76(67 \%)$ & \\
\hline Shunt op & & \\
\hline New placement & $66 / 72(92 \%)$ & \\
\hline Complete/combined revision & $10 / 16(62 \%)$ & \\
\hline Proximal revision & $6 / 16(38 \%)$ & \\
\hline Distal revision & $4 / 10(40 \%)$ \\
\hline
\end{tabular}

shunt infection. Other known reasons for early distal catheter failure included abdominal pseudocyst and intraabdominal adhesions.

\section{Discussion}

Some evidence exists to support delaying abdominal surgery after shunt placement in adults, ${ }^{28}$ but most discussion has centered on case reports ${ }^{5,12,15,41,44}$ and small case series $^{9,38,47}$ not limited to pediatric patients. To address the lack of information regarding the treatment of patients requiring abdominal and shunt operations in succession, we endeavored to identify whether abdominal surgery before shunt placement was related to shunt survival time. Our analysis revealed that patients undergoing shunt operations within 2 weeks after abdominal surgery were at increased risk for shunt failure when compared with those who had not had abdominal surgery.

The reason for shunt failure in the setting of recent abdominal surgery is unclear, but there did not appear to be a relationship between abdominal surgery and infection in our cohort. Of the 5 patients to experience shunt failure after a shunt operation following abdominal surgery, only 1 was suspected to have shunt infection. The overall infection rate for this cohort was slightly higher than expected ${ }^{48}$ but was within ranges given in previous studies. ${ }^{2,49}$ As patients with frequent complications are more likely to receive follow-up care, excluding patients without sufficient records may have eliminated some of the patients who fared better from our analysis. Past studies have consistently reported infection and obstruction as the most common causes of shunt failure overall in pediatric patients..$^{30,40}$

Intraabdominal processes known to occur following surgery may account for the relationship between recent
TABLE 4. Analysis of variables associated with shunt malfunction

\begin{tabular}{lcc}
\hline \multicolumn{1}{c}{ Study Variable } & Adjusted HR $(95 \% \mathrm{Cl})$ & $\mathrm{p} \mathrm{Value}$ \\
\hline Abdominal op & Ref & - \\
\hline No previous abdominal op & $3.5(1.3-9.6)$ & 0.01 \\
\hline $\begin{array}{c}\text { Abdominal op }<2 \text { wks before } \\
\text { shunt }\end{array}$ & $1.0(0.9-1.1)$ & 0.84 \\
\hline Age (per yr of age) & $1.6(1.1-2.6)$ & 0.05 \\
\hline Etiology & Ref & - \\
\hline Spinal dysraphism & & \\
\hline Other causes & $5.8(2.3-15.6)$ & $<0.01$ \\
\hline Shunt op & $2.3(0.8-6.4)$ & 0.11 \\
\hline New placement & Ref & - \\
\hline Complete/combined revision & $1.4(0.4-5.0)$ & 0.63 \\
\hline Proximal revision & & \\
\hline Distal revision &
\end{tabular}

abdominal surgery and shunt failure. Residual inflammation from abdominal surgery has been documented in children ${ }^{23}$ and may lead to more adhesions and impairment of CSF absorption. Distal shunt failure has been linked to chronic inflammation and foreign body reaction, ${ }^{4,6,34}$ and recent abdominal surgery may consequently leave patients more susceptible to shunt obstruction.

Another possibility is that manipulation of bowel could lead to the introduction of enteric microorganisms into the peritoneum, where they remain for a limited period of time. Authors of an earlier study similarly proposed ascending infection as a mechanism of shunt failure, relating to observations in pediatric brain tumor patients after percutaneous endoscopic gastrostomy (PEG) tube placement. ${ }^{18}$ Some types of anaerobic bacteria point toward intraperitoneal infection, and could offer insight into infectious source. ${ }^{7}$ Efforts have been made in recent years to improve culturing protocols and improve culture sensitivity, ${ }^{3}$ but the microorganisms involved still cannot always be reliably identified. As such, patients are sometimes treated for shunt infection based on clinical suspicion in the absence of positive cultures.

Overall survival rates of shunts in this study are comparable to those in the existing literature. ${ }^{1,39,43}$ Shunt survival in children continues to improve, and recent advances in operative protocols have been an important factor in reducing infection and failure rates..$^{19,21,22,36,42} \mathrm{In}$ other studies, various hydrocephalus etiologies have been shown to influence the risk of shunt failure within the first year, $, 82,27,35,45$ although etiology has not been a universally significant risk factor. ${ }^{33,43}$ In this study there was an association between shunt placement for hydrocephalus due to spinal dysraphism and shunt failure, with other etiologies not appearing to confer increased risk.

Interestingly, in our multivariate model, no significant individual association was evident between patient age at shunt placement/revision and time to shunt failure, despite seemingly significant differences in the univariate analysis. Previous studies have suggested patient age at 
TABLE 5. Clinical characteristics of 7 patients who underwent shunt operation $\leq 2$ weeks after abdominal surgery

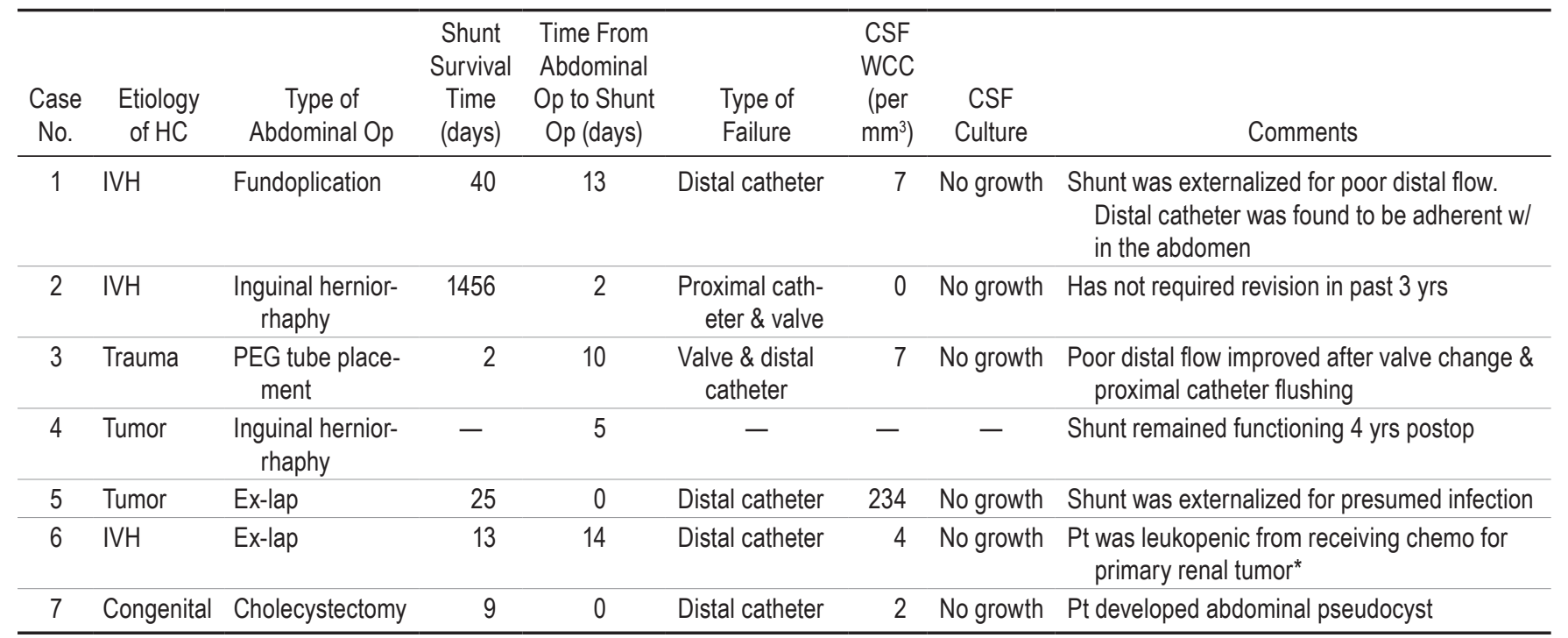

chemo = chemotherapy; IVH = intraventricular hemorrhage; WCC $=$ white cell count.

* Abdominal tumor was located remotely from shunt catheter and not found to be the cause of distal obstruction intraoperatively. Notably, removal of this case would not affect the reported statistical significance of shunt surgery $\leq 2$ weeks after abdominal surgery $(p=0.01$ vs $p=0.04)$.

first placement as an independent risk factor for shunt failure. , $14,25-27,31,32,45$ One potential reason for this difference is that our cohort does not exclusively contain first-time placements as do cohorts of some other studies..$^{10,17,24,37}$

Our multivariate analysis suggested that first-time placement was associated with risk of failure, independent of age. This was not an expected finding. A number of past studies have noted no relationship between firsttime placement and shunt failure, ${ }^{11,25,46}$ in contrast, another found first-time placement to confer lower risk of failure. ${ }^{1}$ One possible explanation for our result is the duration of our study. Stone and colleagues ${ }^{43}$ previously noted that a small, but significant percentage of first-placement shunts survive beyond 10 years. As the mean follow-up for our study was about 5 years, our first-placement survival times may not fairly represent some shunts that survived much longer. Nevertheless, first-placement status and recent abdominal surgery ( $\leq 2$ weeks prior to shunt surgery) appear to be independently related to shunt failure.

The mechanism behind shunt failure in the setting of abdominal surgery may remain difficult to elucidate without more accessible, sensitive testing for pathogens. Other limitations of this study are those inherent to retrospective analysis, and larger studies may uncover additional relationships not addressed here. Indeed, a larger study may be necessary to fully elucidate the relationship between abdominal surgery and shunt malfunction. Our study spanned 7 years and included review of over 500 pediatric shunt cases, yet after necessary exclusions were made, only 7 patients were identified as having had shunts placed shortly after abdominal surgery. However, given that short-term shunt failure in pediatric patients remains a major challenge within pediatric neurosurgery and can strongly impact patient outcomes, we believe our initial exploration of the relationship between shunt failure and recent abdominal surgery warrants further investigation.
Our data suggest that patients could benefit from avoidance of peritoneal catheter placement for up to 2 weeks following abdominal surgery when possible, but the small size of the study calls for a cautious interpretation.

\section{Conclusions}

Ventriculoperitoneal shunt surgery shortly after abdominal surgery appears to be associated with shorter shunt survival. When feasible, some patients who require shunt surgery within the first 2 weeks after abdominal surgery might benefit from the use of atrial or pleural termini.

\section{Acknowledgments}

Sixia Chen was funded in part by NIH (National Institute of General Medical Sciences, Grant 1 U54GM104938).

\section{References}

1. Al-Tamimi YZ, Sinha P, Chumas PD, Crimmins D, Drake J, Kestle J, et al: Ventriculoperitoneal shunt 30-day failure rate: a retrospective international cohort study. Neurosurgery 74:29-34, 2014

2. Ammirati M, Raimondi AJ: Cerebrospinal fluid shunt infections in children. A study on the relationship between the etiology of hydrocephalus, age at the time of shunt placement, and infection rate. Childs Nerv Syst 3:106-109, 1987

3. Arnell K, Cesarini K, Lagerqvist-Widh A, Wester T, Sjölin $\mathrm{J}$ : Cerebrospinal fluid shunt infections in children over a 13year period: anaerobic cultures and comparison of clinical signs of infection with Propionibacterium acnes and with other bacteria. J Neurosurg Pediatr 1:366-372, 2008

4. Arnell K, Olsen L: Distal catheter obstruction from noninfectious cause in ventriculo-peritoneal shunted children. Eur J Pediatr Surg 14:245-249, 2004

5. Baskin JJ, Vishteh AG, Wesche DE, Rekate HL, Carrion CA: Ventriculoperitoneal shunt failure as a complication of laparoscopic surgery. JSLS 2:177-180, 1998 
6. Baumgartner FJ, Moore TC, Mitchner J: Recurrent ventriculoperitoneal shunt pseudocyst in a nine-year-old girl. Klin Wochenschr 68:485-487, 1990

7. Brook I: Meningitis and shunt infection caused by anaerobic bacteria in children. Pediatr Neurol 26:99-105, 2002

8. Buster BE, Bonney PA, Cheema AA, Glenn CA, Conner AK, Safavi-Abbasi S, et al: Proximal ventricular shunt malfunctions in children: Factors associated with failure. J Clin Neurosci 24:94-98, 2016

9. Cairns A, Geraghty J, Al-Rifai A, Babbs C: Percutaneous endoscopic gastrostomy and ventriculoperitoneal shunts: a dangerous combination? Dig Endosc 21:228-231, 2009

10. Caldarelli M, Di Rocco C, La Marca F: Shunt complications in the first postoperative year in children with meningomyelocele. Childs Nerv Syst 12:748-754, 1996

11. Chern JJ, Bookland M, Tejedor-Sojo J, Riley J, Shoja MM, Tubbs RS, et al: Return to system within 30 days of discharge following pediatric shunt surgery. J Neurosurg Pediatr 13:525-531, 2014

12. Cobianchi L, Dominioni T, Filisetti C, Zonta S, Maestri M, Dionigi P, et al: Ventriculoperitoneal shunt and the need to remove a gallbladder: Time to definitely overcome the feeling that laparoscopic surgery is contraindicated. Ann Med Surg (Lond) 3:65-67, 2014

13. Cochrane DD, Kestle J: Ventricular shunting for hydrocephalus in children: patients, procedures, surgeons and institutions in English Canada, 1989-2001. Eur J Pediatr Surg 12 (Suppl 1):S6-S11, 2002

14. Cozzens JW, Chandler JP: Increased risk of distal ventriculoperitoneal shunt obstruction associated with slit valves or distal slits in the peritoneal catheter. J Neurosurg 87:682-686, 1997

15. Damrah O, Naik P, Fusai G, Sharma D: Is laparoscopic cholecystectomy safe for acute cholecystitis in the presence of ventriculo-peritoneal shunt? Int J Surg Case Rep 2:157-158, 2011

16. de Jong TP, Chrzan R, Klijn AJ, Dik P: Treatment of the neurogenic bladder in spina bifida. Pediatr Nephrol 23:889896, 2008

17. Di Rocco C, Marchese E, Velardi F: A survey of the first complication of newly implanted CSF shunt devices for the treatment of nontumoral hydrocephalus. Cooperative survey of the 1991-1992 Education Committee of the ISPN. Childs Nerv Syst 10:321-327, 1994

18. Gassas A, Kennedy J, Green G, Connolly B, Cohen J, DagEllams U, et al: Risk of ventriculoperitoneal shunt infections due to gastrostomy feeding tube insertion in pediatric patients with brain tumors. Pediatr Neurosurg 42:95-99, 2006

19. Kanev PM, Sheehan JM: Reflections on shunt infection. Pediatr Neurosurg 39:285-290, 2003

20. Kestle J, Drake J, Milner R, Sainte-Rose C, Cinalli G, Boop F, et al: Long-term follow-up data from the Shunt Design Trial. Pediatr Neurosurg 33:230-236, 2000

21. Kestle JR, Holubkov R, Douglas Cochrane D, Kulkarni AV, Limbrick DD Jr, Luerssen TG, et al: A new Hydrocephalus Clinical Research Network protocol to reduce cerebrospinal fluid shunt infection. J Neurosurg Pediatr 17:391-396, 2016

22. Klimo P Jr, Van Poppel M, Thompson CJ, Baird LC, Duhaime AC, Flannery AM: Pediatric hydrocephalus: systematic literature review and evidence-based guidelines. Part 6: Preoperative antibiotics for shunt surgery in children with hydrocephalus: a systematic review and meta-analysis. J Neurosurg Pediatr 14 (Suppl 1):44-52, 2014

23. Lapthorne S, Bines JE, Fouhy F, Dellios NL, Wilson G, Thomas SL, et al: Changes in the colon microbiota and intestinal cytokine gene expression following minimal intestinal surgery. World J Gastroenterol 21:4150-4158, 2015

24. Lee JK, Seok JY, Lee JH, Choi EH, Phi JH, Kim SK, et al: Incidence and risk factors of ventriculoperitoneal shunt in- fections in children: a study of 333 consecutive shunts in 6 years. J Korean Med Sci 27:1563-1568, 2012

25. Liptak GS, Masiulis BS, McDonald JV: Ventricular shunt survival in children with neural tube defects. Acta Neurochir (Wien) 74:113-117, 1985

26. Liptak GS, McDonald JV: Ventriculoperitoneal shunts in children: factors affecting shunt survival. Pediatr Neurosci 12:289-293, 1985-1986

27. McGirt MJ, Zaas A, Fuchs HE, George TM, Kaye K, Sexton DJ: Risk factors for pediatric ventriculoperitoneal shunt infection and predictors of infectious pathogens. Clin Infect Dis 36:858-862, 2003

28. Nabika S, Oki S, Sumida M, Isobe N, Kanou Y, Watanabe Y: Analysis of risk factors for infection in coplacement of percutaneous endoscopic gastrostomy and ventriculoperitoneal shunt. Neurol Med Chir (Tokyo) 46:226-230, 2006

29. Notarianni C, Vannemreddy P, Caldito G, Bollam P, Wylen $\mathrm{E}$, Willis B, et al: Congenital hydrocephalus and ventriculoperitoneal shunts: influence of etiology and programmable shunts on revisions. J Neurosurg Pediatr 4:547-552, 2009

30. Park MK, Kim M, Park KS, Park SH, Hwang JH, Hwang SK: A retrospective analysis of ventriculoperitoneal shunt revision cases of a single institute. J Korean Neurosurg Soc 57:359-363, 2015

31. Piatt JH Jr: Cerebrospinal fluid shunt failure: late is different from early. Pediatr Neurosurg 23:133-139, 1995

32. Piatt JH Jr, Carlson CV: A search for determinants of cerebrospinal fluid shunt survival: retrospective analysis of a 14-year institutional experience. Pediatr Neurosurg 19:233242, 1993

33. Raffa G, Marseglia L, Gitto E, Germanò A: Antibiotic-impregnated catheters reduce ventriculoperitoneal shunt infection rate in high-risk newborns and infants. Childs Nerv Syst 31:1129-1138, 2015

34. Rainov N, Schobess A, Heidecke V, Burkert W: Abdominal CSF pseudocysts in patients with ventriculo-peritoneal shunts. Report of fourteen cases and review of the literature. Acta Neurochir (Wien) 127:73-78, 1994

35. Reddy GK, Bollam P, Caldito G, Guthikonda B, Nanda A: Ventriculoperitoneal shunt surgery outcome in adult transition patients with pediatric-onset hydrocephalus. Neurosurgery 70:380-389, 2012

36. Rehman AU, Rehman TU, Bashir HH, Gupta V: A simple method to reduce infection of ventriculoperitoneal shunts. J Neurosurg Pediatr 5:569-572, 2010

37. Riva-Cambrin J, Kestle JR, Holubkov R, Butler J, Kulkarni AV, Drake J, et al: Risk factors for shunt malfunction in pediatric hydrocephalus: a multicenter prospective cohort study. J Neurosurg Pediatr 17:382-390, 2016

38. Roeder BE, Said A, Reichelderfer M, Gopal DV: Placement of gastrostomy tubes in patients with ventriculoperitoneal shunts does not result in increased incidence of shunt infection or decreased survival. Dig Dis Sci 52:518-522, 2007

39. Shannon CN, Carr KR, Tomycz L, Wellons JC, Tulipan $\mathrm{N}$ : Time to first shunt failure in pediatric patients over 1 year old: a 10-year retrospective study. Pediatr Neurosurg 49:353-359, 2013

40. Simon TD, Hall M, Riva-Cambrin J, Albert JE, Jeffries HE, Lafleur B, et al: Infection rates following initial cerebrospinal fluid shunt placement across pediatric hospitals in the United States. Clinical article. J Neurosurg Pediatr 4:156-165, 2009

41. Smiljanić A, Adam VN, Mrsić V, Cala Z, Kovacević M, Markić A: [Laparoscopic cholecystectomy in patients with ventriculoperitoneal shunt.] Lijec Vjesn 133:260-262, 2011 (Croatian)

42. Spader HS, Hertzler DA, Kestle JR, Riva-Cambrin J: Risk factors for infection and the effect of an institutional shunt protocol on the incidence of ventricular access device infec- 
tions in preterm infants. J Neurosurg Pediatr 15:156-160, 2015

43. Stone JJ, Walker CT, Jacobson M, Phillips V, Silberstein HJ: Revision rate of pediatric ventriculoperitoneal shunts after 15 years. J Neurosurg Pediatr 11:15-19, 2013

44. Torigoe T, Koui S, Uehara T, Arase K, Nakayama Y, Yamaguchi K: Laparoscopic cecal cancer resection in a patient with a ventriculoperitoneal shunt: A case report. Int J Surg Case Rep 4:330-333, 2013

45. Tuli S, Drake J, Lawless J, Wigg M, Lamberti-Pasculli M: Risk factors for repeated cerebrospinal shunt failures in pediatric patients with hydrocephalus. J Neurosurg 92:31-38, 2000

46. Villavicencio AT, Leveque JC, McGirt MJ, Hopkins JS, Fuchs HE, George TM: Comparison of revision rates following endoscopically versus nonendoscopically placed ventricular shunt catheters. Surg Neurol 59:375-380, 2003

47. Wadhwa S, Hanna GK, Barina AR, Audisio RA, Virgo KS, Johnson FE: Gastrointestinal cancer surgery in patients with a prior ventriculoperitoneal shunt: the department of veterans affairs experience. Gastrointest Cancer Res 5:125-129, 2012

48. Yogev R: Cerebrospinal fluid shunt infections: a personal view. Pediatr Infect Dis 4:113-118, 1985
49. Yogev R, Davis AT: Neurosurgical shunt infections. A review. Childs Brain 6:74-81, 1980

\section{Disclosures}

The authors report no conflict of interest concerning the materials or methods used in this study or the findings specified in this paper.

\section{Author Contributions}

Conception and design: Mapstone. Acquisition of data: Burks, Conner, Briggs, Bonney. Analysis and interpretation of data: Burks. Drafting the article: Burks. Critically revising the article: Mapstone, Conner, Briggs, Glenn, Bonney, Cheema, Gross. Reviewed submitted version of manuscript: Mapstone, Burks. Approved the final version of the manuscript on behalf of all authors: Mapstone. Statistical analysis: Burks, Chen.

\section{Correspondence}

Timothy B. Mapstone, Department of Neurosurgery, University of Oklahoma Health Sciences Center, 1000 N Lincoln Blvd., Ste. 4000, Oklahoma City, OK 73104.email: timothy-mapstone@ ouhsc.edu. 